\title{
Comparison of Music Education in Schools between China and the U.S.
}

Fu Lili

\author{
Department of Art, Hainan College of Software Technology, Qionghai, Hainan, China (3701911@qq.com)
}

\begin{abstract}
The differences between China and the U.S. are analyzed in terms of the understanding of the culture, description of the relation between the culture and the music education, and the discussion of the history of the music education. Problems are identified via comparison. Next, differences and similarities between the two countries in terms of the culture and music education are investigated. The vision for the future of music education in China is provided.
\end{abstract}

Keywords — China and the U.S., schooling, music education

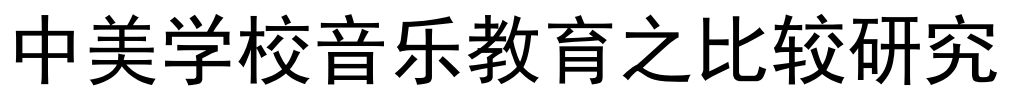

符丽莉

海南软件职业技术学院艺术传媒系，琼海，海南，中国

摘 要 本文主要通过对文化的理解、对音乐教育的认识、对文化与音乐教育关系的描述、对音乐教育历史发展的阐述等方面进 行比较, 分析中美两国在音乐教育上的区别, 通过比较发现问题。针对发现的问题, 在两国文化和音乐教育的异同上进行分析、描述, 提出一点设想, 展望我国音乐教育的未来发展。

关键词 中美, 学校教育, 音乐教育

\section{1. 引言}

中国文化源远流长, 自古代就非常重视音乐和人文教 育, 对中国人的思维方式和行为影响较大。夏、商、周时 期, 中国音乐教育就已经开始了; 到秦代, 各种学术包括 音乐教育已经十分活跃; 汉代, 开始了音乐机构的建设, 更是逐步推动了音乐教育的发展; 各民族广泛的音乐交流 开始于南北朝时期; 在唐代, 中国当时已经是世界文化及 教育的交流中心, 音乐教育更是达到了高度繁荣; 宋元和 明清时期, 音乐教育没有明显的发展和突破; 再到近代, 国民党政府教育部当时颁布了一系列关于音乐教育课程开 设的教育法律法规, 之后在中国, 音乐教育与政治、经济、 文化等方面共同发展[1]。在学校音乐教育方面, 培养了一 大批优秀的音乐教育专业人才。

我国民族众多, 音乐教育与文化相互融合也由来已久， 自古代就强调 “礼乐” 对人的教化作用, 到现代的音乐教 育更是与文化不可分割。美国同中国一样, 也是多民族融 合的国家, 居民大多从欧洲各地移民过去, 各种文化交相 辉映, 形成多民族的文化熔炉。本文试着通过比较发现在 文化或者音乐教育方面两国的异同之处。

\section{2. 中国音乐教育理念的发展}

中国文化历史悠久, 开设音乐教育是世界上最早的。 在古代音乐教育已经被列为 “六艺” 之礼、乐、书、数、 射、御的第二位, 因此下文中涉及的学校音乐教育是指从 广义上所理解的学校二字, 更多是指古代开设音乐教育的 机构 ${ }^{[2]}$ 。中国音乐教育从古至今, 都是以人为主的音乐教 化思想, 更多强调个人艺术修养和道德行为的培养, 并有 “兴于诗,立于礼,成于乐” 的说法。中国近现代, 音乐教育 受到西方世界教育理念的影响, 但都是对中国古代音乐教 育理念的集成与发扬。

\section{1 远古至战国时期}

根据考古和现存文献资料显示, 新石器时代已经出现 了早期的音乐教育, 当时我们的祖先大多使用一些原始的 乐器, 伴随着祭祀仪式活动的音乐活动; 另一方面, 他们 为了协调劳动动作、统一节奏、为了思想的交流等, 出现 了一些劳工的声音, 在劳动实践中把音乐与实践相互结合, 这便是古代音乐学校的倠形, 但大多还是从事官方音乐或 者民俗活动居多。 
夏朝至战国时期, 在官方的学校里, 音乐教育除了进 行音乐活动的教育外, 更突出文化修养方面的潜移默化的 影响。西周时期的音乐机构通常只培养王室成员, 民间能 够参与学习的人少之又少。而且, 当时的音乐教育理念掺 杂了一些政治意义上的统治而设立的教育。周朝音乐教育 更多地为了排除人民对统治者反抗的态度, 以更好的维护 社会安定和等级制度。春秋战国时期, 学术界百家齐鸣。 音乐教育逐步扩散到普通民众, 以孔子为代表的儒家更是 奠定了中国音乐教育发展的基础。孔子提出 “移风易俗莫 善于乐”, “兴于诗, 立于礼, 成于乐”, 同时他认为音乐教育 应强调道德和审美相结合的教育, 这是音乐文化追求的体 现, 音乐教育的发展与社会文化的需求在当时是相一致的。

\section{2 秦朝时期至南北朝时期}

秦至汉代, 在多民族的统一国家中间, 汉族文化逐渐 演变成为文化的中心, 在其他民族多方面的参与下, 中国 音乐文化呈多元化发展趋势。汉代时期的音乐教育推崇儒 家礼乐教育, 强调音乐对人的教化作用。儒学音乐教育理 论主要是学习歌舞技艺等各种音乐知识, 并非为统治阶级 培养治国之才, 只享受音乐带来的乐趣, 这种教育观念在 中国音乐教育的发展史上有着不容忽视的作用 ${ }^{[3]}$ 。

南北朝时期的音乐教育, 有秦汉时期的特点, 同时也 因为当时历史大动荡的年代, 音乐方面也出现民族多样文 化大融合局面。当时出现大量迁徙, 各民族杂居和混乱的 年代里, 各种民族音乐文化也都得到了充分的交流, 不同 的民族音乐文化在很长一段时间内, 吸取其他民族文化的 优点, 发展各自的音乐文化。一些音乐文化开始在私人家 中盛行, 这些都引到了学校音乐教育理念的转变, 更趋向 于民间性和技艺型。

\section{3 隋唐时期至宋朝时期}

隋唐时期国内各民族友好相处, 各少数民族音乐不断 传入中原, 汉族音乐也不断向四面八方传播, 与亚洲其他 国家交流多, 音乐人才不断往来于各民族国家之间, 进一 步促进了国内各民族文化多样性的发展 ${ }^{[4]}$ 。在隋唐时期的 音乐教育机构中, 阶级理念逐渐淡化, 关注音乐自身发展 规律和音乐对人自身修养的提高逐渐增多。到宋代, 音乐 教育机构没有发生变化, 但音乐文化发展的重心由原来的 宫廷音乐活动逐步转向民间, 音乐教育自此脱离了 “官” 体制, 口传心授的音乐教育方式逐步兴起。

\section{4 明清时期}

明代, 音乐教育在官方音乐机构和民间传习同时展开, 这一时期的音乐教育以追求演奏技巧传承为中心。明中叶,
资本主义经济发展迅速, 城市繁荣, 戏曲、曲艺兴盛一时, 这一时期的教育以民间互相交流、学习为主。明清时期, 社会斗争复杂, 音乐表现与以往也有所不同。民主主义思 想在民间音乐的创作中有所反应, 自由收集民歌的风气风 行一时。明清时期专业的音乐教育活动逐步走出宫廷, 民 间也出现了一些音乐教育机构, 教授和传播音乐。

清代的音乐教育更注重音乐的实际用途, 大力提倡雅 乐, 在民间艺人中, 说唱戏曲的成长和发展, 从某种程度 上满足了人民群众日益旺盛的民俗活动和日常生活中的音 乐文化需求。

\section{5 近代学校音乐教育}

19 世纪中叶鸦片战争后, 西方列强的侵略反倒助长了 中国在政治、经济、文化等方面的改革, 中国人民在反抗 的过程中促进了中国音乐教育的新生。从一些外国传教士 创办的教会学校开设音乐课开始, 我国的学校音乐教育也 随之发展。当时, 洋务代表的改革者在新学校开设音乐课, 借以调动人民的爱国主义热情, 以此振奋人心, 激励年轻 人。学校音乐教育的教学理念倡导学习新文化, 冲破旧风 俗, 提倡自由的教育。

\section{6 现代学校音乐教育}

1921 年中国共产党的成立, 带动中国进入了新的历史 时期 ${ }^{[5]}$ 。随着教育的不断需要, 普通的学校音乐教育在中 小学呈现发展势头, 蔡元培提出的美育颇为深入人心, 专 业音乐学校也逐步兴起。在一些师范院校和专业院校中逐 步开设音乐科系, 这些学校和教会学校培养出来的音乐人 才大多充实到普通音乐教育领域。1923 年颁布的《课程设 置纲要》, 提出了各个阶段不同的教育理念, 要求音乐教育 以培养学生的团结精神、奋发进取的精神、欣赏音乐的兴 趣、发扬仁爱的民族精神等为主。这一时期的中国专业教 育属于初创阶段, 后期的音乐教育发展, 上海国立音专贡 献巨大。

\section{7 当代学校音乐教育}

中华人民共和国建国以来, 我国音乐教育得到了空前 的进步和发展, 同时音乐教育也在向着现代化的方向发展。 当代的学校音乐教育也可以分为三个阶段, 建国后的 17 年 里 (1949 年到 1966 年), 在教育旧体制改造和新体制建设 方面, 政府颁布了一系列的法律法规, 确定了美育和音乐 教育在整个教育中的地位, 至此我国的音乐教育步入正轨; 第二个阶段是文化大革命的十年, 在这个各方面动荡的时 期, 音乐教育陷入混沌不堪的状态, 学校音乐教育没有得 到任何发展; 第三个历史时期是 1978 年十一届三中全会至 
今, 在十一届三中全会的指导方针的引领下, 美育在学校 教育中的地位逐步上升, 《中小学音乐课程教学大纲》和《音 乐课程标准》不断完善, 2011 年颁布的《义务教育音乐课 程标准》提出的教育理念为 ${ }^{[6]}$ 面向全体学生, 注重个性发 展, 使每个学生都得到音乐潜能的开发, 并从中受益。

\section{3. 美国音乐教育理念的发展}

美国是个移民国家，在不同肤色、不同宗教信仰、不 同语言以及不同文化碰撞凝结的美国文化, 对美国音乐教 育影响巨大。正因为存在不同民族之间多元文化的碰撞, 美国音乐教育在不同时期表现内容也有所不同。

\section{1 早期歌咏学校}

十八世纪殖民地时期前, 美国的学校音乐教育呈现的 形式多以社区歌咏学校为主, 早期歌咏学校主要为了宗教 的传教需要设立 ${ }^{[7]}$ 。第一所歌咏学校出现在 1717 年, 教师 多为牧师担任, 教学内容多为演唱圣歌和讲读圣经, 这对 美国音乐的长期发展奠定了一定的基础, 它成为美国早期 学校音乐教育的基石。

\section{2 学校音乐教育的成立}

随着经济的蓬勃发展和社会的进步, 首先在学校举办 音乐教育的是美国学校音乐教育之父的鲁尔.梅森, 他强调 音乐教育对智力因素的影响, 同时也重视音乐教育对人的 身心健康的帮助, 所以第一所学校音乐教育的提出是为发 展人教育人而提出的, 与音乐本身无关 ${ }^{[8]}$ 。但由于当时美 国相关政府部门认为音乐培养不是普通民众的事, 更应该 是对天才儿童的培养, 因此导致当时的学校音乐教育发展 缓慢。

\subsection{9 世纪的音乐教育}

19 世纪, 美国经济得到了空前发展, 此事才开始提出 在学校教育的基础上开设音乐教育。在学校教育中, 音乐 教育的辅助性质得到了强调, 比如音乐可以帮助老师维持 课堂纪律, 音乐可以培养孩子的审美能力, 音乐是一种有 价值的智力训练、能够为未来的生活奠定良好的的文化基 础等等。这一时期的音乐交流开始变得异常频繁, 开始学 习其它国家的教学方法、模式等, 更是推动了音乐教育的 发展。民众普遍认为音乐能够增进不同民族之间的相互理 解和融合, 促进社会和谐发展, 因此对音乐的培养目的则 更加重视多民族音乐对文化交流、民族认同的作用，开始 显露出多民族音乐文化教育的作用了。

\section{4 中期美国音乐教育}

二十世纪的美国学校音乐教育趋向于多元化的形式。 二十世纪上半叶, 美国学校音乐教育的目的在于辅助提高
公民素质，促进合作等。1946 年美国音乐教育界提出音乐 的培养目标中, 明确指出音乐教育要重视儿童对器乐的兴 趣、激发孩子学习积极性, 培养他们对音乐的热爱和欣赏, 可以看出这些要求都是从审美的角度提出来的。此时的美 国学校音乐教育在种族多样性交流的环境下，除了让培养 目标变得多元起来, 而且音乐课程从最初的辅助地位发展 为具有价值的课程, 因此, 培养创造性思维能力的音乐教 育理念在这个时期得到了确定。

\section{5 后期美国音乐教育}

二战后，音乐教育开始情调在对音乐的审美中来体验 音乐, 原先关注儿童的音乐教育开始转向关注大众音乐教 育。20 世纪 60 年代中期, 出现了 “曼哈顿维尔音乐课程 方案”, 其重点强调实践, 希望学生通过自身实践变成学习 的主体, 成为自己成长的评价者 ${ }^{[9]}$ 。这一时期, 多 “文化 中的音乐教育” 和 “音乐教育中的文化” 得到了共同发展, 这种多元文化中的音乐教育促进了美国音乐教育的发展。

\section{6 当代美国音乐教育}

2000 年, 克林顿政府的美国教育法案承认, 包括音乐 在内的艺术课程是基本教育学科, 具有和数学、历史、政 治等相同地位的学科。美国《艺术教育国家标准》规定了 三个不同阶段学生的培养目标, 三个阶段分别是幼儿园至 四年级、五年级至八年级、九年级至十二年级, 这三个阶 段中, 学生达到每个阶段特定学习目标后, 方可进入下一 阶段的音乐学习。通过唱歌、乐器演奏和综合性的表演, 学生可以尽情表达自己的感情, 丰富他们的生活。学生通 过声乐器乐的学习培养了他们的毅力、培养了他们学习新 事物的能力、丰富了知识开阔了眼界, 全方位的提升了学 生的个人素质。

总体来讲, 美国的学校音乐教育由重视音乐审美开始, 到后来, 音乐教育开始转向认识自身独特价值, 强调在审 美的过程中来体验音乐, 当代美国教育则强调学生同学音 乐学习提高自己的审美为目的。

\section{4. 美国音乐教育对中国音乐教育发展的启示}

\section{1 突出音乐教育的 “创造性” 思维}

美国学校音乐教育模式众多, 百花齐放, 每个学区不 同的教学标准、不同的教材, 甚至于同一学区不同学校、 同一学校不同教师所采用的教材、教学方法不尽相同。但 是, 不同教学模式、教学方法下都有一个明确的目的一一 “创造” [10]。在 “创造” 为主题的教育模式下, 鼓励学生 在音乐学习过程中主动探索和创新。例如奥尔夫教学法和 柯达伊教学法, 在音乐教育的过程中实现了多民族多元文 化相互融合的局面, 在教学过程中强调学生创造性思维的 
激发, 都收到了很好的教学效果。

伴随着我国经济的迅猛发展, 教育也已经逐步步入国 际化的时代, 因此, 学习美国的学校音乐教育, 让音乐教 育的发展围绕创造这一国际认同的主题, 最大程度激发学 生的学习热情和创造力。

\section{2 凸显音乐文化的教育意义}

美国音乐文化具有多元性的特点, 他们在音乐教育过 程中会对音乐文化做深入探讨, 使学生在了解音乐文化的 同时，提高音乐欣赏、艺术审美的能力等。

音乐与文化的相互融合, 有助于扩展学生的文化视野, 促进学生对音乐的感受, 提高学生音乐欣赏、创造思维以 及艺术审美的能力。因此, 教学过程开展以音乐文化为主 题的音乐欣赏、实践等, 能够对学生学习音乐起到促进作 用。

\section{3 明确音乐教育的目的不仅是教授音乐}

著名音乐教育家卡尔 - 奥尔夫说过, 音乐教育是人的 教育。美国学校音乐教育的目的是为了提高国民素质、培 养人的创造性, 而不是为了培养音乐家而设立的。1 996 年 美国政府立法, 音乐作为中小学的必修课, 与数、理、化、 文、史同等重要，成为基础教育的六门学科。

在我国, 音乐教育虽然已经开始成为全民素质教育中 的一个重要方面, 但实施过程令人堪忧。普通中小学的音 乐教育要么当成专业音乐教育实施, 要么根本不重视。音 乐作为使人情感宣泄的手段和渠道, 在素质教育中应该大 力提倡。我们应该在美国学校音乐教育中得到启示, 在艺 术教育中应有目的的把素质教育作为教育目标, 体现人的 全面发展，而不是关注音乐本身。

\section{4 多样性的音乐教育模式}

美国学校音乐教育中, 奥尔夫教学法、柯达伊教学法、 达尔克罗斯教学法和综合音乐感教学法占主导地位。这些 教学模式各有特点, 又能够交融混合。这些教学模式早已 被吸收为美国音乐教育体系的组成部分。美国在实施 “创 造” 主体的教育过程中, 不局限本土音乐教育模式, 而是 大胆吸收先进的音乐教育模式, 结合自身国家的文化背景, 逐步兼容，形成美国式的音乐教育模式。

在我国, 虽然很早开始引进外来的音乐教育模式和方 法, 成效甚微。原因有二, “传统” 的教学观念根深蒂固; “本土” 观念强。应该学习我们老祖宗对待外来文化的态 度, 古时候的 “胡乐”、“高丽乐” 都能被引进融入本土音 乐, 唢呐、琵琶等都能转化为汉族的民族乐器。因此, 学 习外来的先进音乐教育模式并不会有损于我国本土的音乐 内容和风格, 应学会接纳并未我国的素质教育服务。在学
习过程中, 不能生搬硬套, 应结合我国实际传统文化, 对 外来音乐教育模式做到兼容、消化, 变成自己的东西。

\section{5 多样性的音乐教育内容}

2001 年联合国教科文组织第 31 届会议上通过的《世 界文化多样性宣言》, 标志着全球提倡文化多样性的共识已 经达成。多样性的文化发展是一个民族生存和延续的条件, 同时也是世界文化得以发展的基础。

我国 56 个民族，不同民族、不同地区经济文化差异较 大, 在实施全民素质教育这方面, 有必要采用多样性的音 乐教学内容来发展我国的基础音乐教育, 不同地区、不同 学校、不同教师根据民族特点、地区特点找到适应本区域 或不同学生熟悉、感兴趣的音乐教育内容, 才符合多民族 的中国国情。

\section{5. 小结}

比较来看中美两国音乐教育的发展历史, 无论是发展 阶段、发展特点还有文化背景的比较中, 都可以看出中美 两国的音乐教育存在共性, 也存在差异。现在是一个研究 成果互相分享的时代, 我国在保持额头有民族音乐文化的 同时, 也可以学习国外先进的音乐教育经验, 对中国音乐 教育的进一步发展起到促进作用。

\section{参考文献(References)}

[1] Zeng Suijin. Sociology of Music. Shanghai: Shanghai Conservatory of Music Press ,2004,pp.103-205

[2] Wang Lili. The School Music Education on China and USA From a Variety of Cultural Perspectives. FuJian: Fujian Normal University, 2012,pp.17-32

[3] Xiu Hailin. Music Education in Ancient China (New Edition). Shanghai: Shanghai Education Press, 2011

[4] Cao Deben. Traditional Culture of China and the Diverse Cultures of the World. Journal of Tsinghua University (Philosophy and Social Sciences Edition), 2001

[5] Yu Yuzi. The Music Education of Modern Schools in China (1840-1949) (New Edition). Shanghai: Shanghai Education Press, 2011

[6] The Ministry of Education. Standard of Music Course for Compulsory Education, 2011

[7] Dai Dingcheng. Prospect of Music Education. Shanghai: East China Normal University Press, 2001

[8] Harold Albert Ellis. The Theory of Music Education (Second Edition). Central Conservatory of Music Press, 2008,pp.38-105

[9] Liu Pei .The Survey of music education in USA. Shanghai: Shanghai Education Press, 2011,pp.169-189

[10] Yingying Gu. A Comparative Study of Chinese and American Music Education from Cultural Perspective. Qufu, Qufu Normal University, 2008, pp.30-45 